\title{
Function and structure in the paired fins of scorpaeniform fishes
}

\author{
William A. Gosline \\ Museum of Zoology, University of Michigan, Ann Arbor, MI 48109, U.S.A. \\ Received 13.10.1993 Accepted 28.2.1994
}

Key words: Pectoral fin, Pelvic fin, Teleosts

\section{Synopsis}

The paircd fins of the basic, ancestral type of free-swimming acanthopterygian tcleost serve primarily in guiding the forward course of movement and in maneuvering within the water column. In various scorpaeniform fishes the paired fins have taken on a number of other functions associated with a bottom-living mode of life. Among these are: defense against predation, probing for food items, propping the forward part of the body away from the bottom, progressing over it, digging into it, and the development of a suction disc for attachment to it. The relationship between these developments and paired-fin structure is the subject of the paper.

\section{Introduction}

The main line of teleostean evolution has passed through a series of free-swimming forms. From these, bottom-living groups have evolved repeatedly: siluroids and aulopiform fishes among lower teleosts and a whole series of higher teleosts, e.g., gobioids, blennioids, flatfishes, trachinoids, callionymoids, gobiesocoids, and most scorpaeniform fishes. This shift in the mode of life involves a host of functional and structural changes. Only those having to do with the paired fins are considered here. The discussion is further limited to the scorpaeniform fishes, the group that shows the greatest diversity in paired-fin modification for a substrate-associated existence (Table 1).

In free-swimming fishes the paired fins serve primarily to guide the forward course through the water and to maneuver within the water column, but these functions lose their importance in a fish that spends much of its time in contact with the substrate. In the benthic scorpaeniform fishes, the release from the selection pressure on the paired fins for guiding and maneuvering has led to a remarkable radiation in other directions.

Any work discussing function should optimally be based on the observation of living fishes. Unfortunately, observations on the use of the paired fins in living scorpaeniform fishes are only incidental for some groups and totally lacking for others. For the latter it is necessary to fall back on suggestions concerning function based on preserved specimens, as is done here (see Appendix for a list of species examined and their place in scorpaeniform classification). Such a procedure is notoriously treacherous, but it at least has the merit of setting up testable hypotheses when observations of living forms become available. It also serves to draw attention to certain functional problems and to the variety of fish capabilities.

\section{Pectoral fins}

Many scorpaeniform fishes, e.g., Scorpaena (Breder 1963) and apparently Choridactylus (see Fig. 1 in 
Table 1. Principal types of adaptation in the paired fins of bottom--living scorpaeniform fishes, with examples.

\begin{tabular}{lll}
\hline Type of adaptation & Example & Structure involved \\
\hline $\begin{array}{l}\text { Defense } \\
\text { Fin expansion } \\
\text { Warning coloration }\end{array}$ & $\begin{array}{l}\text { Dactyloptena (Dactylopteridae) } \\
\text { Inimicus (Scorpaenidae) }\end{array}$ & $\begin{array}{l}\text { Pectoral fins } \\
\text { Progression }\end{array}$ \\
$\begin{array}{l}\text { Clambering } \\
\text { Hopping } \\
\text { 'Walking' }\end{array}$ & $\begin{array}{l}\text { Agonomelas (Agonidae) } \\
\text { Bhamphocottus (Cottidae) }\end{array}$ & Pectoral fins \\
$\quad$ Quadripinnate & Dactyloptena (Dactylopteridae) & Pectorals and pelvic girdle \\
$\begin{array}{l}\text { Perching } \\
\text { Vertical perch }\end{array}$ & Zanclorhynchus (Congiopodidae) & Pelvic fins and girdle \\
Horizontal prop & Cottus (Cottidae) & Pectoral and pelvic fins \\
Digging & Synchirus (Cottidae) & Pelvic fins \\
Attack position & Inimicus (Scorpaenidae) & Pelvic fins \\
Resting position & Prionotus (Triglidae) & Pelvic fins \\
Suction disc & Liparis (Liparidae) & Pelvic fins \\
\hline
\end{tabular}

Eschmeyer et al. 1979b), expand their pectoral fins as a threat display. In some of these the pectoral fins have become greatly enlarged: Pterois, dactylopterids, Prionotus (Fig. 1c). (The dactylopterid method of escaping, at least from a human observer, is to swim slowly away with the pectorals laterally extended, personal observation). However, the pectoral expansion in each of these three groups has de-

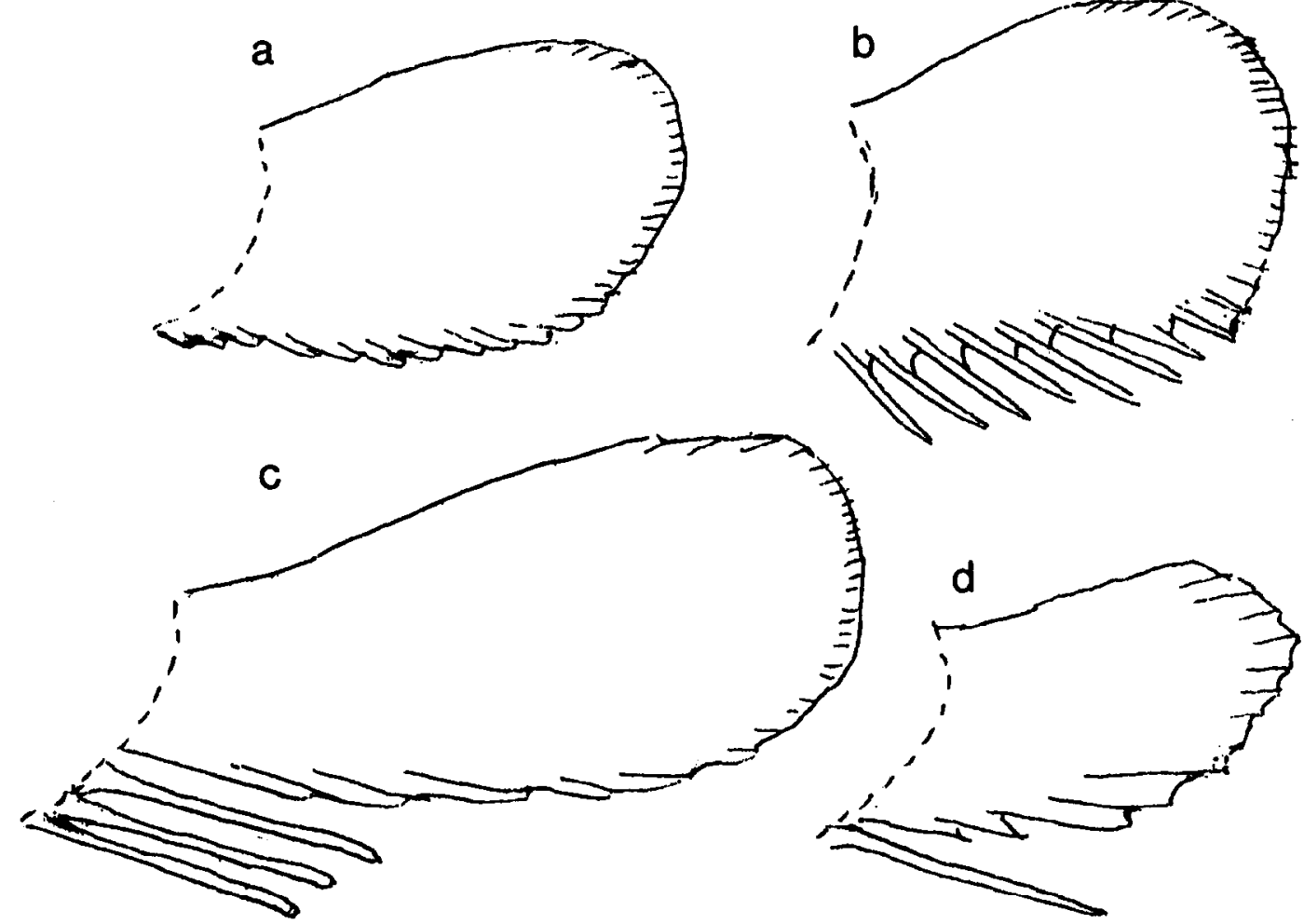

Fig. 1. Left pectoral fins of a - Scorpaena guttata, b-Helicolenus maderensis with the fin spread downward, $\mathrm{c}-$ Prionotus roseus, and dMinous monodactylus. 

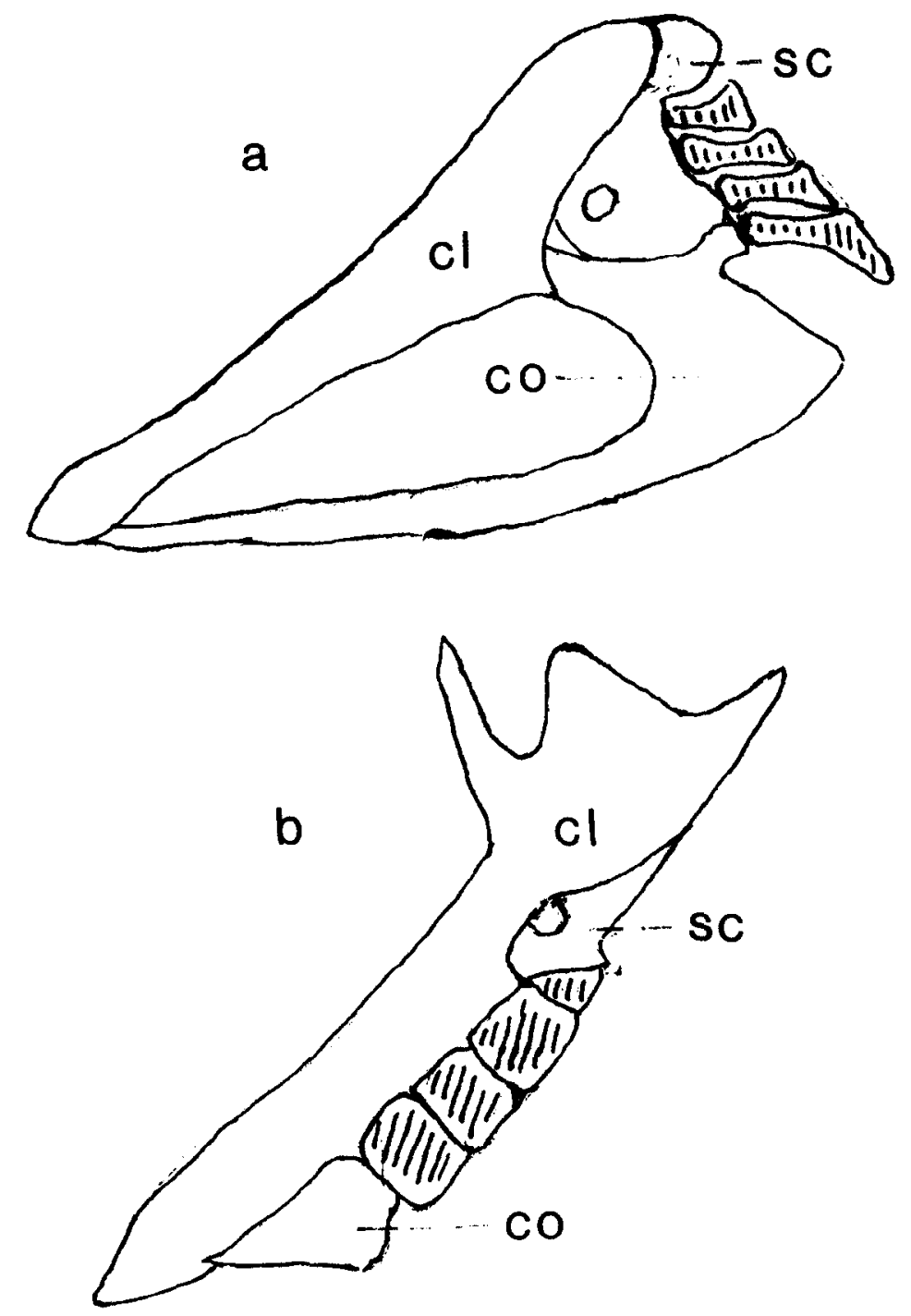

Fig. 2. Left pectoral girdles, based on figures in Starks (1930), of a - Dactyloptena volitans, and b-Prionotus strigatus. Actinosts with vertical lines. $\mathrm{C} 1=$ cleithrum, $\mathrm{co}=$ coracoid, and $\mathrm{sc}=$ scapula.

veloped in a different way. In Pterois, a free-swimming scorpaenid, the pectorals are basically a great enlargement of the type of fin found in percoids. In Dactyloptena and Prionotus the wing-like pectorals are held flat as the fish moves over the level substrate, but the construction of the 'wings' is very different in the two genera. In Dactyloptena, as in most fishes, the uppermost rays form the leading edge of the extended fins; in Prionotus a lower pectoral ray provides the leading edge (Fig. 1c). In Dactyloptena the pectoral fin base slants down and back. This slant is caused in part by the progressively longer lower actinosts (Fig. 2a) with which the rays artic- ulate. Furthermore these longer lower actinosts provide a swivel joint at the fin base which makes it possible for Dactyloptena to move the lower part of the fin relative to the upper (in Dactyloptena anterior) part. That Dactyloptena does make differential movements in parts of the pectoral fin is indicated by the very complex fin musculature (Grenholm 1923, Figs. 112-115) and by aquarium observations (Breder 1963). In Prionotus the pectoral fin base slants down and forward so that the lower rays extend out ahead of the upper when the fin is extended; the actinosts are all small and united to form a rigid posterior border to the pectoral girdle (Fig. 
2b); and the fin musculature is little differentiated except for that to the three lower free rays.

As with a number of other bottom-living teleosts, the pectoral fins of most scorpaeniform fishes are broad and rounded (Fig. 1) rather than of the relatively narrow, falcate type of most free-swimming forms. Such broad fins, extended laterally as the fish is at rest on the bottom, provide it with a strong standing start when the pectorals are clapped back abruptly against the sides. A further feature of such fins is modification of the lower ray tips in association with their substrate contact.

These pectoral developments in scorpaeniform and other bottom-living groups are also associated with a change in the part of the pectoral girdle with which the rays articulate, the actinosts. There is a general, if somewhat gradual and erratic trend in scorpaeniform fishes away from the progressively longer lower actinosts that provide the swivel-joint in free-swiming percoids and the scorpaeniform Dactyloptena (Fig. 2a) to one in which the actinosts are all equally long and firmly united, forming, with the scapula above and the coracoid below (Fig. 2b), a continuous, rigid posterior border to the pectoral girdle (for examples of the pectoral girdles in various scorpaeniform fishes, see figures in such authors as Starks 1930, Matsubara 1943 and Yabe 1985). The results of this change is to provide the lower pectoral rays with a firm, rather than a flexible base.

Along with this development of a continuous, rigid posterior rim to the girdle, the pectoral ray bases of scorpaeniform fishes often spread out onto the scapula above the actinosts and, e.g., in liparids, onto the coracoid below them. In the extreme instance of the cottid genus Synchirus the pectoral fins spread down and forward to the midventral line.

One group of scorpaeniform fishes, the Platycephalidae and Bembridae, has the relatively narrow pectoral fins of free-swimming percoids, and the lower pectoral rays show no morphological indication of contact with the substrate. That this pectoral development is secondary in the group is indicated by the small, firmly united actinosts (see Starks 1930).

Among the many scorpaeniform fishes in which the lower pectoral rays are modified by contact with the substrate, the simplest type of modification is that represented in such genera as Scorpaena (Fig. 1a) or Cottus. Here the lowest pectoral rays are short, unbranched, and have somewhat fleshy, upturned tips. In such fishes the normally extended pectorals probably serve as lateral props to keep the fish upright and to provide the fish with the rapid standing-start mentioned above. From here, one line of further modification in the pectoral fins leads morphologically to the cottoid genera Agonomelas and Rhamphocottus. The former uses its pectoral fins to clamber around among the seaweed, and Rhamphocottus 'virtually jumps and crawls around on the bottom' (Eschmeyer et al. 1983, p. 182). The 'jumping' in this short-bodied fish is probably caused by the pectoral fins, with the specialized pelvic girdle (Yabe 1985) serving as a landing platform between hops.

What may be a different line of modification seems to be initiated in Sebastes and is carried somewhat farther in Helicolenus (Fig. 1b). In these genera the lower pectoral rays are again unbranched, but are not shortened and extend out beyond the interradial membranes. The musculature to these lower rays is of the same type as that to the upper rays, but the muscles to the individual lower rays appear to be better separated from one another than those to the rays above. That the pectoral fin of Helicolenus can be spread downward is clear from a preserved specimen in the equivalent of rigor mortis.

To what extent, if any, the lower pectoral rays of Sebastes are in contact with the substrate seems open to question. This large genus has a number of species living sympatrically, some close to the bottom and some farther up in the water column. In preserved specimens I can see no difference in lower pectoral rays between Sebastes atrovirens and $S$. chrysomelas which live close to the bottom (Hallecher \& Roberts 1985) and S. melanops, S. mystacinus, and $S$. chrysomelas which live above them.

A more complete separation of the lower pectoral rays occurs in various scorpaeniform groups. Such rays serve different purposes. In some, of which the triglids (Bardach \& Case 1965) and liparids (Sakurai \& Kido 1992) are best known, the lower rays are used as sensory probes for locating food 
items. In liparids such rays make up a more or less separate lower lobe of the pectoral fin. In triglids a few of the anterior rays are completely free from one another and from the rest of the fin (Fig. 1c). The separation of these lower rays occurs during the ontogeny of the individual (Morril 1895). In the adult fish their musculature is completely separate from that of the rest of the fin (Grenholm 1923) and provides them with a greater ability to swing farther anteriorly than the rest of the rays. That the free pectoral rays of Prionotus and Trigla are also used for 'walking' over the substrate has frequently been postulated, but Morrill (1895) questioned that they are really used in such a fashion.

Scorpaeniform fishes that have free anterior pectoral rays but do not seem to use them for sensory purposes are the genera Choridactylus, Inimicus, Minous and Apistus. In Choridactylus (Samuel 1961) and Inimicus the free rays are known to be used in progressing across the substrate, and in Inimicus they seem to serve also as a sort of springboard for attacks on prey swimming above (Eschmeyer et al. 1979b, Fig. 9). As compared with the free ray of Minous (see below) the two free rays of Inimicus are relatively short and firm, and have a much heavier musculature at their bases.

In Minous (Fig. 1d) and Apistus the single free pectoral ray is long and tapered, and in the former genus its tip is covered by a peculiar, deciduous 'cap' or 'glove' (Eschmeyer et al. 1979a). Regarding Apistus, Poss (personal communication) writes: 'I have seen pictures of Apistus carinatus in a German aquarium journal (unable to quote exact source) that appear to show this species proceeding forward to corral prey, much as in Pterois, with the greatly elongated pectoral extending forward and the free ray pointing forward and down, evidently touching or extending into the substrate. The fish swims about half a body length above the bottom with the head pointing down toward the substrate. . These fishes are taken over relatively soft bottoms in prawn trawls in number. Although I have no direct observations to prove this, my suspicion is that unlike most scorpaenids, but like Pterois, this species is an active forager moving about from place to place rather than lying in wait.'

\section{Pelvic fins}

The pelvic fins of scorpaeniform fishes have become adapted to contact with the substrate in various ways, all of them morphologically derived from the typical free-swimming percoid-like fish with a spine and five soft rays.

At one extreme the pelvic fins have been completely lost. This has happened in several scorpaeniform groups, for apparently different reasons. One such group, the Comephoridae, is a secondarily pelagic family restricted to Lake Baikal. In the Liparidae, most genera have the pelvic fins united into a suction disc, but in Careproctus the disc is reduced in size and in Paraliparis it is completely absent, presumably because members of these two genera live over soft bottoms where a suction disc would not function. Cottids usually prop their bodies above the substrate by means of pelvic fins, but Ascellichthys, without pelvic fins, seems to hug the bottom.

In the Liparis-Cyclopterus group the pelvic fins have developed into a suction disk, as noted above. This disc consists of an ovate, median, fleshy plate with raised border areas (Fig. 3b) superimposed on the fins. The fins themselves extend back close to one another and usually contain a spine and five soft rays (Kido 1988) but are otherwise highly modified. The spine and rays are greatly curved (Fig. $3 b$ ), and the rays are unbranched and unsegmented.

The suction disc is limited to the Liparis-Cyclopterus group in scorpaeniform fishes, but the initial morphological stages from which such a disc might develop are present in such fishes as the scorpaenid Synanceia. Here the two pelvic fins extend back close to one another and form a cavity between them. Extending the fins increases the size and depth of the cavity, for the spines swing downward and outward whereas the inner rays are pulled upward by the strongly developed extensor proprius muscles (Grenholm 1923).

Another type of pelvic-fin use is adopted in most cottids, agonids, and apparently in the unrelated aploactids. Here, the outer rays are extended forward and downward (Fig. 3d), rather than laterally, providing a sort of perch that raises the front of the body above the substrate. Such a perch increases the fish's field of vision as well as reducing the 

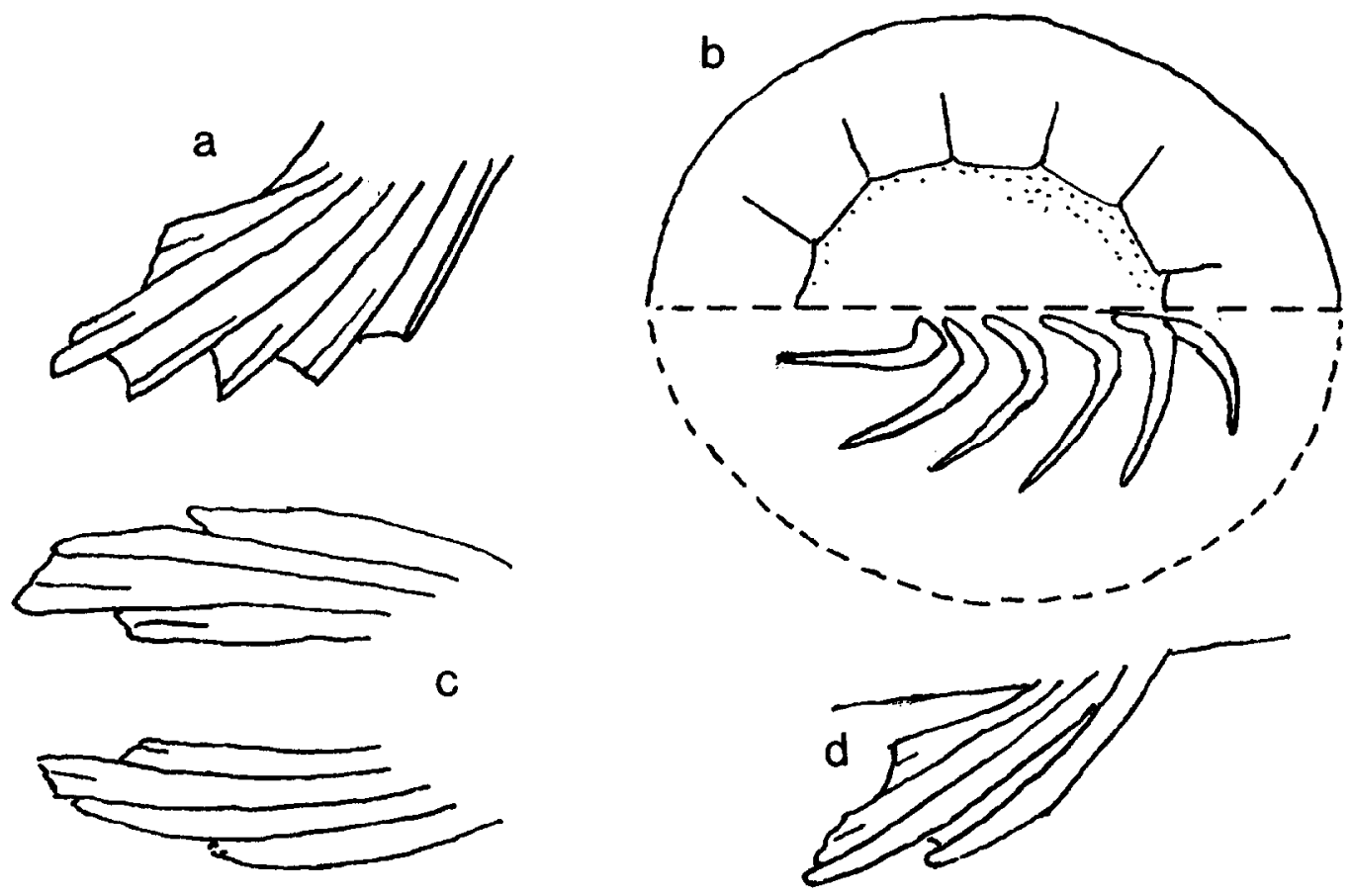

Fig. 3. a - Left pelvic fin extended laterally of Prionotus roseus, from below, b - suction disc of Liparis mucosa from below (the fleshy cover has been removed from the left side to show the underlying rays), $c$-pelvic fins of Cottus carolinae from below, and $\mathrm{d}$-from the side to show the fin extended downward.

amount of contact between the body and the bottom. The two pelvic fins are close together (Fig. 3a), with the outer rays fleshy; the rays are almost always reduced in number; and the M. extensor proprius is lost (Yabe 1985).

This perching habit seems to have evolved within the Cottidae, for the pelvic fins in a basal genus Scorpaenichthys have the usual five soft rays and differ very little in structure from those of the generalized type found in such genera as Sebastes. The perch-like modification has become further adapted in various ways within the Cottidae. In Synchirus the pelvic fins are used as a backwardly-extending prop to wedge the fish against the substrate while the pectorals are moved back toward them (Clemens \& Wilby 1946). The landing-platform function of the pelvic girdle in Rhamphocottus has already been mentioned.

In the scorpaeniform family Dactylopteridae the pelvic fins are much as in the Cottidae, but the musculature to the fin-rays and the structure of the pelvic girdle are so complex (Grenholm 1923, Figs 107110 ) that the pelvic fins may be used for some addi- tional purpose, presumably 'walking' as noted in living individuals by Longley (in Longley $\&$ Hildebrand 1941).

Dactylopterids use a bipinnate method of progress. However, in the congiopodid Zanclorhynchus the pelvic fins have become posteriorly displaced and the fish moves over the bottom by using both pelvic and pectoral fins in a fashion compared to a 'slow trot-like walk' (Andriashev 1993, p. 136).

A final function in which the pelvic fins are at least sometimes involved is excavation. Some scorpaeniform fishes are known to partially bury themselves in the sand: Prionotus (Bardach \& Case 1965, Fig. 7) and Inimicus (Eschmeyer et al. 1979b, Fig. 10). Others very probably do, for example, the platycephalids and bembrids which bear a close general resemblance to such known partial-buriers as the non-scorpaeniform callionymids. Inimicus uses a partly buried position to ambush prey (Eschmeyer et al. op cit.), but Prionotus appears to partially cover itself with sand when at rest. Inimicus excavates 'by a rocking of the body and a pushing of sand from underneath the body by the large pelvic fins' (Esch- 
meyer et al. 1979b, p. 496). Prionotus, with its large, flat-based, widely separate pelvic fins (Fig. 3a) uses the same body-rolling technique (Morrill 1895).

\section{Discussion}

In many ways marine fishes that live in habitual contact with the substrate occupy a different world from that of the fishes that swim over them. The differences involve such aspects of existence as feeding methods, defense against predation, locomotion, and often respiration and reproduction. These differences seem to be more highly developed in the sea than in fresh water, perhaps because almost all freshwater fishes live relatively close to the bottom, but even here the cattishes have a number of structural features that suggest adaptations to a benthic mode of life. In the sea there are also numerous forms that lead an intermediate type of existence between the substrate and the open water above. Such forms exist among the scorpaeniform fishes under consideration here as well as elsewhere.

Among the groups that have become adapted to a bottom-living existence some, like the eels, flatfishes, or gobiesocids, have developed numerous minor adaptations superimposed on a single, basal type of modification for a bottom-living mode of life. The scorpaeniform fishes, by contrast, appear to have tried out a whole series of ways of living on the bottom. Although the changes associated with these different trials also involve various structural and behavioral systems, their variety is well indicated by the paired fins (Table 1) under consideration here.

In free-swimming acanthopterygians the paired fins are of a more or less standardized type, as noted above, and carry out functions in which the use of the two fin-pairs are generally coordinated. In the bottom-living scorpaeniform fishes the two fin pairs may be coordinated in function, as in the congiopodid Zanclorhynchus, or they may be completely separate, as in the liparids. In the latter group the pelvic fins provide a suction disc when the fish is at rest (Able \& Musick 1976) whereas the pectoral fins provide sensory probes while the fish is actively hunting (Sakurai \& Kido 1992).
Some of the paired-fin modifications have evolved only once, as in those of dactylopterids, whereas others appear to have developed two or more times. Among the latter, the use of pectoral rays as sensory probes occurs in triglids and in the quite different liparids. The use of the pelvic fins as a perch in the cottid-agonid group seems to have evolved elsewhere in the aploactids. Finally the suction disk in the Liparis-Cyclopterus group is unique among the scorpaeniform fishes, but the structural route over which it might have developed is suggested by the pelvic fins of Synanceia.

The various main types of paired-fin modifications may become further modified, as in the cottids Synchirus and Rhamphocottus, but, with one exception, it seems improbable that one main type has led to any other. The exception is the platycephalidbembrid group. Here, unlike other bottom-living scorpaeniform fishes, the pectoral fins show no evidence of contact with the substrate, but, as pointed out above, the small, firmly-united actinosts suggest a secondary development from some group with lower pectoral rays that had such contact.

\section{Acknowledgements}

I am greatly indebted to William Eschmeyer for literature and information on the scorpaeniform fishes, to Stuart Poss for an extensive commentary on the original manuscript, and to James Atz for calling my attention to Andriashev's paper.

\section{References cited}

Able, K.W. \& J.A. Musick. 1976. Life history, ecology, and behavior of Liparis inquilinus (Pisces: Cyclopteridae) associated with the sea scallop, Placopecten magellanicus. U.S. Mar. Fish. Serv. Bull. 74: 409-421.

Andriashev, A.P. 1993. On the quadrupedal mode of locomotion of the Kerguelen congiopodid fish Zanclorhynchus spinifer (Scorpaeniformes, Congiopodidae). Zool. Zhurn. 72(9): 130136. (In Russian).

Bardach, J.E. \& J. Case. 1965. Sensory capabilities of the modified fins of squirrel hake (Urophycis chuss) and sea robins (Prionotus carolinus and P. evolans). Copeia 1965: 194-206.

Breder, C.M. 1963. Defensive behavior and venom in Scorpaena and Dactylopterus. Copeia 1963: 698-700. 
Clemens, W.A. \& G.V. Wilby. 1946. Fishes of the Pacific Coast of Canada. Bull. Fish. Res. Board Can. 68: 1-368.

Eschmeyer, W.N., L.E. Hallecher \& K.V. Rama-Rao. 1979a. The scorpionfish genus Minous (Scorpaenidae, Minoinae) including a new species from the Indian Ocean. Proc. Cal. Acad. Sci. (4) 41: 453-473.

Eschmeyer, W.N., E.S. Herald \& H. Hammann. 1983. A field guide to Pacific Coast fishes of North America. Houghton Mifflin, Boston. 336 pp.

Eschmeyer, W.N., K.V. Rama-Rao \& L.E. Hallacher. 1979b. Fishes of the scorpionfish subfamily Choridactylinae from the Western Pacific and the Indian Ocean. Proc. Cal. Acad. Sci. (4) 41: 475-500.

Grenholm, A. 1923. Die Flossenmuskulatur der Teliostier. Uppsala Univ. Arsskr., Math. Naturvetensk. 2: 1-296.

Hallacher, L.E. \& D.A. Roberts. 1985. Differential utilization of space and food by inshore rockfishes (Scorpaenidae: Sebastes) of Carmel Bay, California. Env. Biol. Fish. 12: 91-110.

Kido, J. 1988. Phylogeny of the family Liparididae, with the taxonomy of the species found around Japan. Mem. Fac. Fish., Hokkaido Univ. 35: 125-256.

Longley, W.H. \& S.F. Hildebrand. 1941. Systematic catalogue of the fishes of Tortugas, Florida. Carnegie Inst. Wash. Publ. 535: 1-311.

Matsubara, K. 1943. Studies on the scorpaenoid fishes of Japan. Res. Inst. Nat. Resources (Tokyo) 1, 2: 1-486.

Morrill, A.D. 1895. The pectoral appendages of Prionotus and their innervation. J. Morph. 11: 177-192.

Sakurai, Y. \& K. Kido. 1992. Feeding behavior of Careproctus rastrinus (Liparididae) in captivity. Jap. J. Ichthyol. 39:110-113.

Samuel, C.T. 1961. The ambulatory mechanism in Choridactylus multibarbatus Richardson. Bull. Centr. Res. Inst. Univ. Kerala 8: 79-84.

Starks, E.C. 1930. The primary shoulder girdle of the bony fishes. Stanford Univ. Publ Biol. Sci. 6: 149-239.

Yabe, M. 1985. Comparative osteology and myology of the superfamily Cottoidea (Pisces: Scorpaeniformes), and its phylogenetic classification. Mem. Fac. Fish., Hokkaido Univ. 32: 1130.

Appendix. Preserved specimens examined. The classification followed is that of Eschmeyer (1990). Catalog numbers in parentheses are those of the University of Michigan fish collections.

\footnotetext{
Suborder Scorpaenoidei

Family Scorpaenidae

Subfamily Sebastinae

Helicolenus maderensis (157067), Maine

Sebastes atrovirens (61645), California; $S$. chrysomelas

(179320) California; $S$. inermis (212669), Japan; $S$.

melanops (182116), Alaska; $S$. miniatus (92533),

California; and S. serranoides (132132), California
}

Subfamily Scorpaeninae

Scorpaena brasiliensis (147688), Dry Tortugas

Subfamily Pteroinae

Pterois volitans (198051), Mariana Is.

Subfamily Apistinae Apistus carinatus (191810), Japan

Subfamily Minoinae Minous sp. (214683), Vietnam

Subfamily Choridactylinae Inimicus japonicus (191837), Japan

Subfamily Synanceinae Synanceia verrucosa (197915), Mariana Is

Family Aploactidae Erisphex potti (191796), Japan

Family Triglidae

Subfamily Triglinae

Prionotus roseus (209204), Georgia

Subfamily Peristediidae

Peristedion truncatus (209210), offshore U.S.A.

Suborder Dactylopteroidei

Family Dactylopteridae

Dactyloptena orientalis (113269), Japan

Dactylopterus volitans (185660), Madagascar

Suborder Platycephaloidei

Family Platycephalidae

Platycephalus indicus (183205), Korea

Suggrundus meerdervorti (198824), Japan

Thysanophrys otaitensis (L85624), Madagascar

Family Bembridae

Bembras japonicus (198915), Japan

Family Hoplichthyidae

Hoplichthys gilberti (183279), Japan

Suborder Cottoidei

Family Cottidae

Ascelichthys abortivus (92929), Oregon

Blepsias bilobus (132832), Alaska

Cottus carolinae (200930), Tennessee

Jordania zonope (95012), Washington

Nautichthys oculofasciatus (106111), Alaska

Rhamphocottus richardsoni (147407), Washington

Scorpaenichthys marmoratus (193310), Oregon

Triglops beani (198663), Japan

Vellitor centropomus (186447), Japan

Family Agonidae

Agonus cataphractus (147314), Norway

Bathyagonus nigripinnis (147411), Washington

Family Cyclopteridae

Subfamily Cyclopterinae

Cyclopterus lumpus (157112), Maine

Subfamily Liparidae

Careproctus scottae (102220), Alaska

Liparis mucosa (63563), California; L. truncata (72787),

Greenland 